\title{
SOBRE LA CONSTITUCIONALIDAD DE LA PROHIBICIÓN DE LAS CORRIDAS DE TOROS EN CATALUNA *
}

\author{
Tomás-Ramón Fernández \\ Universidad Complutense de Madrid
}

RESUMEN. El autor de este artículo somete a un análisis crítico la reciente prohibición de las corridas de toros por el Parlamento catalán. Tras analizar la Ley 3/1988, que supuso un primer paso para la actual prohibición, el autor lleva a cabo una defensa de la fiesta de los toros como parte integrante del patrimonio cultural español. Finalmente, el examen de los títulos competenciales invocados por el legislador catalán, lleva al autor a detenerse en el análisis de la competencia en materia de espectáculos y de protección de animales.

Palabras clave: corridas de toros, espectáculos públicos, protección de animales.

ABSTRACT. The author of this article carries out a critical analysis of the recent prohibition against bullfighting by the Catalan Parliament. After analysing Act 3/1988, which represented the first step towards the current prohibition, the author defends bullfighting as an integral part of Spanish cultural heritage. Finally, when examining the powers which the Catalan legislator makes reference to, the author pauses in order to analyse legislative powers with regard to bullfighting shows and the protection of animals.

Keywords: bullfighting, public shows, protection of animals.

* Fecha de recepción: 28 de enero de 2011. Fecha de aceptación: 20 de febrero de 2011. 


\section{LA PROHIBICIÓN DE LAS CORRIDAS DE TOROS EN CATALUÑA. UNA LARGA HISTORIA}

a prohibición de las corridas de toros decretada por la Ley catalana 28/2010, de 3 de agosto, es el punto final, por el momento al menos, de un largo camino que los nacionalistas catalanes iniciaron en 1988 con la Ley 3/1988, de 4 de marzo, de protección de los animales, cuyo art. 4 prohibió con carácter general «el uso de animales en espectáculos, luchas y otras actividades si pueden ocasionar sufrimiento o pueden ser objeto de burlas o tratamientos antinaturales o bien si puede herir la sensibilidad de las personas que los contemplan», exceptuando expresamente, sin embargo, «la fiesta de los toros en aquellas localidades donde, en el momento de entrar en vigor esta Ley, haya plazas construidas para celebrar dicha fiesta», así como «los corre-bous en las fechas y localidades donde tradicionalmente se celebran».

La Ley 3/1988 declaró de este modo «a extinguir» las corridas de toros en Cataluña al prohibir la construcción de nuevas plazas de toros y la celebración de festejos en plazas «improvisadas», no específicamente construidas para esos fines. Fue éste el primer paso, el que entonces pensaron que podían dar sin tropiezos en espera de un momento mejor en el que terminarían con una fiesta que, aunque haya sido también muy popular en Cataluña, los nacionalistas no admiten o no desean como propia del país que imaginan. Que la prohibición se haya decretado ahora no tiene por qué sorprendernos, porque este modo de actuar se produce sistemáticamente. Es exactamente así, mediante aproximaciones sucesivas, como el art. 6 del nuevo y polémico Estatuto de Cataluña de 2006 ha llegado a declarar que el conocimiento del catalán es un deber de todos los ciudadanos de Cataluña, objetivo que ya anunció en el proceso constituyente la enmienda núm. 106 presentada por la Minoría Catalana («Las demás lenguas de España serán también oficiales en los territorios autónomos de acuerdo con sus respectivos Estatutos. Todos los residentes en dichos territorios tienen el deber de conocer y el derecho a usar aquellas lenguas»), que fue defendida por el Sr. Trías Fargas en la Comisión de Asuntos Constitucionales, en la que fue derrotada por 30 votos en contra y dos a favor, con dos abstenciones, derrota que volvió a producirse en el Pleno el 5 de julio de 1978 por 269 votos en contra, 22 a favor y 26 abstenciones.

Por lo demás, la prohibición había sido ya anunciada a bombo y platillo en la legislatura precedente por dos proposiciones de Ley de Esquerra Republicana de Catalunya y de Iniciativa per Catalunya Verds-Esquerra Alternativa, publicadas respectivamente en los Boletines del Parlamento catalán de 18 y 25 de abril de 2005, que caducaron al término de dicha legislatura. El éxito electoral que ambas agrupaciones obtuvieron en los comicios subsiguientes y su acceso al nuevo Gobierno de la Generalitat convirtió la prohibición en una muerte anunciada, que faltaba sólo escenificar adecuadamente.

Así se hizo de inmediato, con deliberada sutileza, acudiendo a la fórmula de la iniciativa legislativa popular con la que, aparentemente al menos, se pretendió reforzar la legitimidad democrática de la prohibición, al propio tiempo que se ponía un freno, también popular, al intento de extenderla a los corre-bous, que la proposición de Ley presentada por Iniciativa perseguía igualmente. 
Para asegurar la consecución de ambos objetivos, el de la prohibición de las corridas y el de la subsistencia de los festejos populares o corre bous, a la iniciativa legislativa popular de la prohibición de aquéllas se unió la proposición de Ley presentada por Convergencia i Unió para la regulación de éstos. Ambos textos fueron tramitados simultáneamente, aunque al final del trayecto se separaran y fueran votados en fechas diferentes y con apoyos también distintos: la Ley 28/2010, de 3 de agosto, de modificación del art. 6 del Texto Refundido de la Ley de Protección de los Animales, aprobado por Decreto legislativo 2/2008, publicado en el Diario Oficial de la Generalitat, de 6 de agosto, y en el Boletín Oficial del Estado del siguiente día 24, y la Ley 34/2010, de 1 de octubre, de regulación de las fiestas tradicionales con toros, publicada en el Diario Oficial de la Generalitat, de 8 de octubre, y en el Boletín Oficial del Estado del día 23 del mismo mes.

Como dato curioso merece la pena resaltar que al pie de ambos figura la firma de un cordobés, el Honorable Sr. Montilla, paisano, por tanto, de los grandes «califas» del toreo, Rafael Molina Lagartijo, Rafael Guerra Guerrita, Rafael González Machaquito, Manuel Rodríguez Manolete y Manuel Benítez El Cordobés.

Mucho más curioso que esto, que, al fin y al cabo, es una simple anécdota, es el contraste que ofrecen las dos Leyes o, para ser más exactos, los preámbulos de las mismas en los que pretenden exponerse las razones que las sustentan.

El de la Ley prohibitiva 28/2010 es extraordinariamente enfático y pretencioso. Comienza recordando que la vigente Ley catalana 22/2003 de protección de los animales considera que éstos «son organismos dotados de sensibilidad física y psíquica» y de ello extrae la conclusión, que la Ley de 2003 no había extraído, de que la nueva Ley «debe establecer una protección integral de todos los animales y no puede dejar al margen espectáculos como las corridas de toros, ya que objetivamente implican un maltrato al animal y le provocan dolor, padecimiento y, por último, la muerte».

Los festejos populares o corre-bous también implican objetivamente un maltrato al animal y le provocan dolor y padecimiento durante los quince minutos o incluso media hora que el público les acosa sin descanso, pero ello no impide que se autoricen porque, según proclama el preámbulo de la Ley 34/2010, «el toro enmaromado, los toros en la calle, las habilidades en la plaza, el toro embolado y las vaquillas marcan todo el ritmo festivo de un acontecimiento extraordinario, propio de las raíces más profundas de Cataluña» y, además, «el flujo económico que esta tradición reporta, los puestos de trabajo que genera y el patrimonio genético inconmensurable de la cría y selección que los humanos efectuamos de estos animales motivan que este acontecimiento sea único».

Al parecer, los dos meses que separan a la Ley 34/2010 de la Ley 28/2010 le han hecho olvidar al legislador catalán «la proximidad genética entre especies» o el hecho de que, al fin y al cabo, «todos los animales somos el resultado de procesos evolutivos paralelos», así como que «el toro (bos taurus) es un animal mamífero con un sistema nervioso muy próximo al de la especie humana, lo que significa que los humanos compartimos muchos aspectos del sistema neurológico y emotivo», declaraciones todas ellas salidas de su pluma para iluminar el preámbulo de la Ley prohibitiva de las corridas de toros. 
Ciertamente entre éstas y los corre-bous hay una diferencia, la muerte del animal lidiado, pero no parece que pueda afirmarse, dada la proclamada proximidad del sistema nervioso humano y el del bos taurus, que el toro sólo sufre y siente dolor en el momento de su muerte, porque, si esa proximidad es cierta, la experiencia humana acredita que los sufrimientos y dolores pueden llegar a ser tan grandes durante la vida que la muerte se sienta como una auténtica liberación.

Si esa proximidad es cierta, no resulta aventurado sospechar tampoco que las reses que, como el novillo de «Calabuig», son transportadas de feria en feria para ser corridas en los festejos populares que la Ley 34/2010 regula con solo veinticuatro horas de separación entre un festejo y otro o, incluso, dos veces en un periodo de veinticuatro horas si se trata de un «toro-cerril» [art. 10.d)], sientan algo parecido.

No es cosa de insistir, sin embargo, porque la inconsistencia de estas contradictorias justificaciones salta a la vista. Son simples envolturas retóricas de unas decisiones sólo inteligibles en clave política: a los promotores de la Ley 28/2010 con la prohibición de las corridas de toros les salían las cuentas, esas cuentas que los políticos están continuamente echando para prever cuántos votos pierden y cuántos ganan con cada medida, mientras que para que esas cuentas les salieran positivas con los corre-bous no sólo no había que prohibirlos, sino que había que «blindarlos», esto es, ratificar mediante una Ley específica la excepción a la prohibición general con la que ya contaban desde la versión inicial de la Ley de Protección de los Animales, de 4 de marzo de 1988.

No se trataba, pues, de otorgar «una protección integral de todos los animales», como proclama el preámbulo de la Ley 28/2010, porque de los que son objeto de la caza y de la pesca dicha Ley no se ocupa en absoluto, cualquiera que pueda ser su proximidad al sistema nervioso de los humanos. F. DE CARRERAS, que es un catalán de pro, un hombre independiente y un excelente constitucionalista ha tenido el valor de decirlo alto y claro en las páginas de La Vanguardia: «Es una gran hipocresía sostener que la decisión catalana nada tiene que ver con la defensa de una supuesta identidad catalana frente a otra supuesta identidad española de la que el toro es símbolo. $\mathrm{O}$, dicho de otra manera, que la causa de la prohibición es únicamente el deseo de proteger al toro como animal y no es también el deseo de marcar una frontera diferencial con el resto de España. También en este caso es cierto que muchos antitaurinos honestos son únicamente defensores de los animales. Pero no es menos cierto que una tal decisión no se hubiera tomado sin este afán de borrar cualquier huella en Catalunya de lo que se considera un símbolo de España. ¿ $\mathrm{O}$ es que derribando el famoso toro de Osborne se estaba simplemente protegiendo a un animal de la tortura en lugar de demoler y desmantelar la alegoría de una presencia indeseada? Quizás el espectáculo de torear no sea éticamente muy edificante, pero tampoco es un crimen y, en todo caso, aún es menos edificante la hipocresía de ciertos diputados al dar unas razones que no son en las que están pensando» (La Vanguardia, 5 de julio de 2010).

Aunque esto es absolutamente evidente, no nos libera, sin embargo, a los juristas de la obligación de preguntarnos si esta, digamos curiosa, Ley prohibitiva de las corridas de toros es o no conforme a la Constitución. Más, en concreto, si puede o no considerarse constitucionalmente posible la referida prohibición y si, en el caso de que lo sea, es o no competente para acordarla un Parlamento autonómico como el de Cataluña. 


\section{LA FIESTA DE LOS TOROS COMO PARTE INTEGRANTE DEL PATRIMONIO CULTURAL ESPAÑOL}

Para responder a estas preguntas es imprescindible comenzar precisando que la fiesta de los toros es parte integrante del patrimonio cultural de España. Traer aquí argumentos y testimonios para avalar esta afirmación es, me parece, innecesario. Requeriría, por lo demás, un tiempo y un espacio excesivos dar cuenta con algún detalle de esa amistad tres veces milenaria del hombre español y el toro bravo a la que se refirió ORTEGA Y GASSET, de la que, por lo demás, existen tantas y tantas pruebas, algunas tan hermosas como esa magnífica miniatura de las Cantigas del Rey Sabio que glosó de forma admirable Á. ÁlVAREZ DE MIRANDA en su obra, ya clásica, Ritos y juegos del toro (Madrid, Taurus, 1962).

Sin ir más lejos sí merece la pena subrayar que esa estrecha relación del hombre y el toro que terminó plasmándose en el toreo a pie tuvo siempre una extensión nacional. No tenía razón en absoluto JovelLANOS cuando en su Memoria de Espectáculos decía interesadamente que la afición a los toros era algo que se circunscribía a la Corte y a lugares concretos de Andalucía. Una historiadora leonesa, I. VIFORCOS (cfr. El León barroco. Los regocijos taurinos, Universidad de León, 1992), demostró cumplidamente hace ya unos años mediante una sistemática revisión de los documentos que se conservan en el Archivo municipal que en el siglo XVII y aún en el XVI se celebraban regularmente en una ciudad tan poco taurina en apariencia como León festejos taurinos en los que intervenían, contratados al efecto por el Ayuntamiento, diestros que ejecutaban las más diversas suertes en todo semejantes a las que por la misma época tenían lugar en Pamplona, uno de los focos reconocidos del toreo popular, es decir, del toreo a pie, cuya historia ha reseñado L. DEL CAMPO a partir también de la riquísima documentación que contiene el Archivo municipal de la capital navarra. G. SANTONJA acaba de hacer un trabajo semejante, enormemente riguroso, que muestra con detalle como se fue afirmando el toreo a pie en las ciudades castellanas en esa misma época [cfr. Luces sobre una época oscura (El toreo a pie del siglo XVII), 2. ${ }^{a}$ ed., León, Everest, 2010].

Desde entonces hasta ahora las corridas de toros se han celebrado con plena regularidad y sin interrupción alguna en toda España, superando las prohibiciones papales contra las que el propio rey Felipe II hubo de alzarse haciéndose eco del clamor popular y las que casi dos siglos después acordaron, primero Carlos III en 1785 a instancia del Conde de Aranda y después, Carlos IV, con su Real Cédula de 10 de febrero de 1805, luego incorporada a la Novísima Recopilación como Ley VII del Título XXXIII del Libro VII.

Esta última prohibición nunca fue formalmente levantada, salvedad hecha de aquella parte de España que durante la Guerra de la Independencia estuvo bajo la Administración del rey José, que, por congraciarse con sus nuevos súbditos, se apresuró a prescindir de ella. La prohibición carolina se ha mantenido, aunque parezca mentira, hasta la Ley Corcuera de 4 de abril de 1991, sobre potestades administrativas en materia de espectáculos taurinos, que devolvió la fiesta al campo de la legalidad.

Durante casi dos siglos, por tanto, la fiesta de los toros vivió y creció en un régimen de mera tolerancia, actitud que es la que expresamente recomendó J. DE BURGOS a los subdelegados de Fomento en su famosa Instrucción de 1832. 
Destaco estos datos porque, en su elementalidad, prueban de forma irrefutable el profundo arraigo de la fiesta en la vida de los españoles durante siglos. De pocas cosas, si alguna, podrá predicarse su pertenencia al patrimonio cultural que contribuye a definir nuestra propia y peculiar realidad, nuestro privativo modo de ser, de entender y de estar en el mundo, nuestra cultura en el sentido más profundo y más auténtico del término, sin la cual sencillamente no seríamos ya nosotros mismos.

Quienes piensen que esto pudo ser así en el pasado, pero que ya hoy no lo es deberían repasar las cifras que tiene publicadas la Mesa del Toro sobre la realidad actual de los festejos taurinos. Se celebran en más de 5.000 municipios, que es tanto como decir en la práctica totalidad de los mismos, si se tiene en cuenta que de los 8.100 municipios hoy existentes en España 3.800 tienen menos de 500 habitantes.

El número actual de festejos asciende a 17.000 y a 35.000 el de las reses lidiadas. Hay más de 1.200 explotaciones ganaderas que ocupan 540.000 hectáreas, en las que pastan 140.000 vacas nodrizas. Todo ello produce unos ingresos directos por temporada del orden de 1.350 millones de euros, a los que hay que sumar otros 1.150 millones de ingresos indirectos, lo que supone una aportación del sector al PIB nacional del 2,4 por $100 \mathrm{y}$ unos 180.000 empleos aproximadamente.

Los tiempos son, ciertamente, otros, pero, aunque así sea y aunque pueda sonar excesivamente enfático, sigue siendo verdad la afirmación de J. BENAVENTE. No podemos saber, en efecto, si España sería mejor o peor sin toros; lo que sí sabemos es que no sería España.

La fiesta de los toros es parte indiscutible de nuestro patrimonio cultural. Si a alguien le parece exagerada esta afirmación no tiene más que leer el art. 46 de la Ley del Patrimonio Histórico Español de 25 de junio de 1985. «Forman parte del Patrimonio Histórico Español — dice- los bienes muebles e inmuebles y los conocimientos y actividades que son o ban sido expresión relevante de la cultura tradicional del pueblo español en sus aspectos materiales, sociales o espirituales». Más claro, imposible.

Si esto es así, que sin duda lo es, resulta forzoso concluir que nadie puede prohibir las corridas de toros, porque todos los poderes públicos sin excepción alguna están expresamente obligados por el art. 46 de la Constitución a garantizar la conservación y a promover el enriquecimiento del patrimonio histórico, cultural y artístico de los pueblos de España y de los bienes que lo integran, cualquiera que sea su régimen jurídico y su titularidad.

Los poderes públicos pueden y, sin duda, deben regular los bienes muebles e inmuebles, los conocimientos y las actividades de todo tipo que forman parte de nuestra cultura tradicional con el fin de asegurar su conservación y su disfrute por los ciudadanos, cuyo acceso a dichos bienes y conocimientos es una auténtico derecho que a todos ellos reconoce el art. 44.1 de la Norma Fundamental, pero, como dijo muy bien nuestro compañero R. MENDizÁbal, regular no es destruir (en el diario El País, de 29 de julio de 2010).

En el marco de una Constitución que hace de la libertad y el pluralismo valores superiores del ordenamiento jurídico no cabe reconocer a autoridad alguna competencia para prohibir ni los carnavales, ni el flamenco, la jota o la sardana, ni los encierros de Pamplona, ni la romería del Rocío, ni las procesiones de Semana Santa, ni ninguna 
otra manifestación cultural. La cultura, como el lenguaje, pertenece al pueblo. Es él exclusivamente quien la crea, la modifica o la transforma. Nadie puede imponérsela contra su voluntad, nadie puede quitársela tampoco. La cultura está en este sentido más allá de la Ley, fuera del alcance de la Ley. Por eso, justamente, la Constitución no ha apoderado a nadie para eliminar manifestación cultural alguna. Por eso, cuando se refiere a la cultura, tampoco ha atribuido a poder o autoridad alguna una competencia exclusiva sobre ella. El deber de garantizar la conservación y promover el enriquecimiento del patrimonio cultural se impone por el art. 46 de la Constitución a todos los poderes públicos. En materia de cultura las competencias son concurrentes y las que las Comunidades Autónomas puedan haber asumido de acuerdo con sus respectivos Estatutos no excluyen en absoluto que el servicio de la cultura tenga que ser considerado por el Estado deber y atribución esencial suya. El art. 149.2 de la Constitución es inequívoco en este sentido.

Desde esta perspectiva resulta, pues, obligado concluir que la Ley catalana 28/2010, de 3 de agosto, es radicalmente inconstitucional.

\section{ANÁLISIS DE LOS TÍTULOS COMPETENCIALES INVOCADOS POR EL LEGISLADOR CATALÁN}

\subsection{Una acumulación puramente retórica}

Aunque lo hasta aquí dicho es suficiente, en mi opinión, para resolver la cuestión, no pueden dejar de analizarse, como es natural, los títulos esgrimidos por la Ley prohibitiva, que dice dictarse «al amparo de los arts. 148 y 149 de la Constitución y de los arts. 46, 116, 141, 144 y 189 del Estatuto de autonomía de Cataluña», esto es, del nuevo y polémico Estatuto de 19 de junio de 2006.

Llama la atención en primer término el abundante número de preceptos constitucionales y estatutarios que la Ley trae a colación, así como la vaguedad e imprecisión de la cita de algunos de ellos, que impide saber el pasaje o pasajes de los mismos en los que el legislador catalán cree haber encontrado amparo. Yo, desde luego, no veo en el art. 148 de la Constitución ninguno que pueda dar cobertura o servir de justificación a la prohibición de las corridas de toros. El apartado 17 se refiere al «fomento de la cultura» y el 19 a «la adecuada utilización del ocio» como materias sobre las que las Comunidades Autónomas pueden asumir competencias, pero no se me ocurre cómo podría encajarse en una de estas rúbricas, que son las únicas que pueden tener alguna relación con el asunto, la prohibición que la Ley 28/2010 proclama, salvo que se tenga una idea paternalista, por no decir totalitaria, acerca del papel de las autoridades en relación a nuestro ocio y a su adecuada administración.

Tampoco acierto a verlo en el art. 149, a menos que lo que quiera decirse sea que sobre todo lo que no esté expresamente enunciado en su apartado 1 corresponda a la Comunidad Autónoma de Cataluña la competencia exclusiva para decidir lo que los órganos de ésta consideren conveniente en cada momento, lo que no es cierto en ningún caso y menos todavía en éste, dados los términos del art. 149.2 al que ya hice referencia. 
La alusión a los arts. 46 y 144 del Estatuto tampoco es más clara. El primero de ellos reitera el reconocimiento que el art. 45 de la Constitución hace con carácter general del derecho a disfrutar de un medio ambiente adecuado, al que el precepto estatutario viene a añadir la referencia al desarrollo sostenible y al equilibrio territorial. No es adivinable, sin embargo, tampoco en este caso, cómo de este derecho puede derivar la prohibición de las corridas de toros, ya que de ella sólo puede resultar la desaparición del bos taurus, que es, precisamente, el que ayuda a mantener el equilibrio territorial de los parajes en los que actualmente se cría, que correrían muy probablemente un grave riesgo el día en que faltara su presencia.

El art. 144, que contempla el mismo tema desde la perspectiva competencial, tampoco ofrece a la prohibición la cobertura que la Ley proclama.

La cita del art. 189 es, en fin, absolutamente enigmática porque este precepto hace referencia al desarrollo y aplicación del Derecho Europeo, que, a diferencia del legislador catalán, nada ha dispuesto nunca contra las corridas de toros. El Protocolo núm. 10, anejo al Tratado de Amsterdam de 2 de octubre de 1997, sobre la protección y el bienestar de los animales, dejó expresamente a salvo, como es notorio, el respeto a «las costumbres de los Estados miembros relativas en particular a hábitos religiosos, tradiciones culturales y patrimonio regional», lo que ha vuelto a ratificar el art. 13 del Tratado de Funcionamiento de la Unión Europea, en la versión resultante del Tratado de Lisboa de 13 de diciembre de 2007. Hoy por hoy tampoco cabe apelar al Derecho europeo para justificar la prohibición de las corridas de toros.

Sólo los arts. 116 y 141 tienen, por tanto, relación con nuestro tema. El primero de ellos atribuye a la Generalidad la competencia sobre la «sanidad vegetal y animal cuando no tenga efectos sobre la salud pública y la protección de los animales». El segundo se refiere a la competencia en materia de juegos y espectáculos «que incluye en todo caso - dice el precepto- la ordenación del sector, el régimen de intervención administrativa y el control de todo tipo de espectáculos en espacios y lugares públicos».

Procede, pues, afrontar el problema desde esta doble perspectiva.

\subsection{La competencia en materia de espectáculos}

La competencia en materia de espectáculos públicos es una típica competencia de policía administrativa, cuyo núcleo es el mantenimiento del buen orden de los mismos y la protección de las personas y bienes de un modo u otro afectados por ellos, lo que incluye, por supuesto, la garantía de los derechos de los espectadores cuando el acceso al espectáculo requiere el pago de un precio al organizador del mismo. En este sentido es explícita la jurisprudencia constitucional (vid., por ejemplo, la Sentencia 148/2000, de 1 de junio), que descarta sin decirlo la inclusión en la policía de espectáculos de componentes de carácter moral (vid. la Sentencia 153/1985, de 7 de noviembre, sobre la asignación del anagrama «S» a los espectáculos artísticos y teatrales cuya temática o contenido pueda herir la sensibilidad del espectador medio), al menos como determinantes de medidas limitativas o prohibitivas, que estarían en contradicción con el pluralismo que es propio de un Estado de libertades. 
La policía de espectáculos así entendida, esto es, las facultades y poderes dirigidos a asegurar un desarrollo ordenado de los mismos, excluidas las medidas extraordinarias o de seguridad pública que van por otro camino (vid. la Sentencia constitucional 54/1990, de 28 de marzo), es lo que se traspasó a las Comunidades Autónomas a partir del Real Decreto de 18 de julio de 1984, dictado para la de Andalucía, que sirvió de modelo para todos los demás.

En este Decreto y en los sucesivos la Administración del Estado se reservó la competencia para «suspender o prohibir espectáculos, manifestaciones deportivas o actividades recreativas, así como clausurar locales por razones graves de seguridad u orden público» y también para «dictar normas básicas de seguridad pública para los edificios e instalaciones en los que se celebren espectáculos y actividades recreativas» y para «dictar las normas que reglamenten los espectáculos taurinos».

Nunca, pues, se transfirió ni a Cataluña ni a ninguna otra Comunidad Autónoma la competencia para prohibir con carácter general una determinada clase de espectáculos y, mucho menos, los espectáculos taurinos. Siempre se entendió que lo transferible a las Comunidades Autónomas y lo transferido a las mismas era sólo la policía de espectáculos entendida en los términos más atrás expuestos. La Ley 10/1991, de 4 de abril, sobre potestades administrativas en materia de espectáculos taurinos, así lo confirma, aunque una interpretación, a mi juicio abusiva, de su poco clara disposición adicional haya dado lugar a la proliferación de Reglamentos taurinos autonómicos, exceso que, sin embargo, en nada desmiente lo hasta aquí dicho.

El propio art. 141 del nuevo Estatuto de Cataluña viene a confirmar también que la Generalitat no tiene competencia para prohibir los espectáculos taurinos como acaba de hacerlo la Ley 28/2010, sino sólo para «la ordenación del sector; el régimen de intervención administrativa y el control de todo tipo de espectáculos en espacios y lugares públicos». Ordenar y regular sí, prohibir, en cambio, ni siquiera con carácter singular por razones graves de seguridad u orden público, pues la competencia para prohibir un espectáculo sigue correspondiendo al Estado.

A lo hasta aquí dicho todavía hay que añadir otras razones de carácter sustantivo, que la jurisprudencia constitucional dejó bien establecidas hace ya muchos años. Esta jurisprudencia arranca de la Sentencia 49/1984, de 5 de abril, que desestimó el recurso de inconstitucionalidad interpuesto por la Generalidad de Cataluña contra la disposición adicional segunda de la Ley 1/1982, de 24 de febrero, por la que se regulan las salas especiales de exhibición cinematográfica, la filmoteca española y las tarifas por licencia de doblaje.

La referida disposición otorgaba al ministro de Cultura la facultad de resolver sobre la calificación de las películas «X» y de arte y ensayo, así como sobre la clasificación de las salas especiales en que hubieran de ser exhibidas, lo que la Generalitat consideraba atentatorio contra las competencias que con carácter de exclusivas le atribuía el art. 9, apartados 4 (cultura) y 31 (espectáculos) de su Estatuto de Autonomía dentro del marco de los arts. 148, apartado 1, núms. 17 (fomento de la cultura) y 19 (adecuada utilización del ocio) de la Constitución.

Así planteada la cuestión, la sentencia comienza descartando por superficial «todo intento de construir sobre la idea de competencia en materia de cultura, concretada al 
art. 148.1.17. ${ }^{a}$, una competencia omnímoda y excluyente», afirmando en su lugar que «más que un reparto competencial vertical, lo que se produce es una concurrencia de competencias ordenada a la preservación y estímulo de los valores culturales propios del cuerpo social desde la instancia pública correspondiente», lo que le lleva a concluir que no puede negarse al Estado la competencia para calificar las películas en función de su interés cultural a los efectos de favorecer su exhibición con desgravaciones fiscales estatales, ya que esta acción de fomento «no cierra el camino al fomento por la Generalidad».

Aclarado esto, la sentencia analiza el problema desde la perspectiva de la competencia en materia de espectáculos, expresión ésta que — dice- «dista mucho de ser suficientemente precisa... en cuanto a los ámbitos con relevancia competencial y susceptible de tratamiento jurídico que debe comprenderse en tal título».

El cine - «y con él otras manifestaciones como el teatro»- es incluible desde luego en la rúbrica cultura y en la rúbrica espectáculos, pero de la consideración del cine como espectáculo no resulta sin más, dice la sentencia, que la calificación de películas deba comprenderse en la regla del art. 148.1.19 de la Constitución (adecuada utilización del ocio) y en la del art. 9.31 del Estatuto (espectáculos) con preferencia a toda otra regla competencial.

En lo que se refiere a la calificación de películas «X» la regla preferente, según la sentencia, es «la que arranca del carácter de limitación... actuando mediante la técnica de prohibición y la de presión económica a través de medidas negativas», lo que — concluye- «requiere un tratamiento básico uniforme». «Tratándose de una limitación que tiene su justificación constitucional en el art. 20.4 de la CE debe garantizarse un mismo contenido básico a esta vertiente negativa de la libertad que proclama el indicado precepto, contenido que atrae a la competencia estatal en el marco del art. $149 \cdot 1 \cdot 1{ }^{a}$, la calificación de las películas "X"».

La competencia en materia de espectáculos, de policía de espectáculos, debe, pues, ceder cuando las medidas negativas de este orden afectan a un derecho o a una libertad fundamental, que exigen un tratamiento básico uniforme, como reclama el art. 149.1.1. a de la Constitución.

Este mismo argumento luce en la Sentencia 153/1985, de 7 de noviembre, relativa a la impugnación por el Gobierno del Decreto catalán 194/1982, de 18 de junio, sobre calificación de los espectáculos artísticos y teatrales.

La sentencia que, lógicamente, reitera la doctrina establecida por la anterior, añade una importante precisión que conviene resaltar ahora. La calificación de los espectáculos artísticos y teatrales por razón de la edad y la consiguiente prohibición del acceso a los mismos supone, según la sentencia, «una limitación a la libertad de representación que va ligada a la libertad de expresión y de creación literaria y artística garantizadas en el art. 20 de la Norma fundamental», porque el derecho a expresar y difundir libremente pensamientos, ideas y opiniones, en lo que a las obras teatrales se refiere, «presupone no sólo la publicación impresa del texto literario, sino también la representación pública de la obra, que se escribe siempre para ser representada». 
Sobre esta base la sentencia concluye, como ya lo había hecho la Sentencia 49/1984, que la limitación de ese derecho hace que cobre carácter preferente la competencia estatal ex art. 149.1.1. ${ }^{\mathrm{a}}$

La doctrina constitucional así establecida es perfectamente aplicable a las corridas de toros, como se advierte sin especial esfuerzo. Al formularla el Tribunal Constitucional tuvo buen cuidado en no limitarla al cine, situando junto a él al teatro y a otras manifestaciones artísticas, entre las que es forzoso incluir al tradicionalmente llamado «arte de Cúchares», porque, al margen de otras consideraciones en las que no puedo entretenerme ahora, así es oficialmente considerado, como lo prueba sin ir más lejos la ya larga lista de Reales Decretos que desde 1996 vienen otorgando con grandes extremos la medalla de oro de las Bellas Artes a los lidiadores más destacados.

También aquí está en juego, por tanto, la libertad de expresión artística que el art. 20 de la Constitución reconoce, como lo está el derecho de acceso a la cultura que el art. 44 de la Norma fundamental garantiza a todos sin excepción, por lo que también aquí resulta obligado concluir que la prohibición de las corridas de toros, expresión indiscutible de nuestra cultura, no puede acordarse al amparo de la competencia sobre la policía de espectáculos de Comunidad Autónoma alguna. Cualquier medida limitativa de los espectáculos taurinos reclama «un tratamiento básico uniforme» por exigencia del art. 149.1.1. a de la Constitución. Y es que, como dijo muy bien E. TiERnO GaLVÁN, los toros no son simplemente un espectáculo, son mucho más que un espectáculo, son un auténtico acontecimiento nacional.

\subsection{La competencia en materia de protección de los animales}

Los Estatutos de Autonomía de primera generación, incluido el de Cataluña, no hicieron referencia alguna a la protección de los animales, por lo que había buenas razones para entender que la competencia en esta materia correspondía al Estado de acuerdo con lo dispuesto en el núm. 3 del art. 149 de la Norma Fundamental.

Pese a ello, el Parlamento de Cataluña, sin invocar título competencial alguno que, ya que no directamente, pudiera proporcionarle algún tipo de cobertura, aprobó el 4 de marzo de 1988 una Ley de Protección de los Animales, en la que, como ya recordé, se incluyó una prohibición general de la utilización de animales en espectáculos que pudieran causarles sufrimientos de la que se exceptuaron, sin embargo, los festejos taurinos siempre que se celebraran en plazas construidas al efecto con anterioridad y los tradicionales corre-bous.

La Ley catalana fue inmediatamente imitada por las demás Comunidades Autónomas, que establecieron idéntica prohibición y exceptuaron igualmente los espectáculos taurinos, aunque lo hicieron pura y simplemente sin limitación o condición alguna, salvo la Ley balear de 8 de abril de 1992, que se pronunció en los mismos términos exactamente empleados por el modelo, y la Ley canaria de 30 de abril de 1991, que exceptuó de modo expreso las peleas de gallos y guardó silencio sobre las corridas de toros.

En las instancias estatales esta proliferación de Leyes autonómicas no tuvo ninguna respuesta, a pesar de que suponían una indiscutible invasión por la razón antes 
dicha del ámbito competencial del Estado. Se consideró, sin duda, que su contenido carecía en general de trascendencia en la relación Estado-Comunidades Autónomas. Ninguna tenía tampoco de facto el tratamiento por ellas dado a las corridas de toros, que, ciertamente, no alteró el estado de cosas existente en Cataluña, Baleares y Canarias, territorios en los que la pérdida de espectadores, sobre todo foráneos, había preparado ya el camino a dicho tratamiento.

Esta era la situación en las vísperas de la tramitación del nuevo Estatuto de Cataluña, que ofrecía a sus promotores una oportunidad óptima de afirmar una competencia disfrutada hasta entonces en precario gracias a la pasividad y a la tolerancia mostrada por las autoridades estatales que, naturalmente, no podían desaprovechar. El Estatuto de 2006 ha incluido así, entre las competencias de la Generalitat, la protección de los animales, dando de este modo una base estatutaria y constitucional a su legislación sobre la materia y, por tanto, a la prohibición de los festejos taurinos resultante de la reforma de aquélla por la Ley que ahora nos ocupa.

Importa mucho en este momento, como es natural, precisar como lo ha hecho, porque de ello depende lógicamente el juicio, positivo o negativo, que deba hacerse de la prohibición de los festejos taurinos en Cataluña que, a su amparo, ha impuesto la Ley 28/2010.

La nueva competencia de la Generalitat para la protección de los animales se ubica en el art. 116 del Estatuto, bajo la rúbrica, «agricultura, ganadería y aprovechamientos forestales», materias que, como es notorio, no tienen otro punto de conexión con las corridas de toros que la relativa a la cría del ganado de lidia. El núm. 1 del precepto califica con carácter general de exclusiva la competencia que atribuye a la Generalitat sobre la agricultura y la ganadería, en la que incluye «la sanidad vegetal y animal cuando no tenga efectos sobre la salud humana y la protección de los animales» [apartado d)], pero la enmarca en el respeto a «lo establecido por el Estado en el ejercicio de las competencias que le atribuye el art. 149.1.13 y 16 de la Constitución».

Quiere esto decir que por exigencia estatutaria esa competencia de la Generalitat para la protección de los animales debe ejercerse en el marco de las bases estatales en materia de sanidad fijadas por el Estado y de las medidas de coordinación que éste pueda adoptar en este ámbito y respetando al propio tiempo las bases de la ordenación general de la actividad económica que, según el apartado 13 del art. 149.1 de la Constitución, corresponde al Estado igualmente fijar.

Está, pues, más allá de toda posible discusión, ya que es el propio texto del Estatuto quien lo afirma, que la competencia de la Generalitat en materia de protección de los animales no es en absoluto ilimitada y que no puede ser ejercida unilateralmente al margen de «los principios básicos del orden económico, que han de aplicarse con carácter unitario» en toda España, por decirlo con las mismas palabras que la Sentencia constitucional de 28 de enero de 1982.

«La efectiva unicidad del orden económico nacional — dice la Sentencia constitucional de 5 de abril de 1990 - requiere la existencia de un mercado único y la unidad de mercado descansa, a su vez, como han señalado las SSTC 96/1984, de 19 de octubre ( $B O E$ de 31 de octubre), fundamento jurídico $3 .^{\circ}$, y 88/1986, de 1 de julio (BOE de 22 de julio), fundamento jurídico $6 .^{\circ}$, sobre dos supuestos irreductibles, la libre 
circulación de bienes y personas por todo el territorio español que ninguna autoridad podrá obstaculizar directa o indirectamente (art. 139.2 CE) y la igualdad de condiciones básicas del ejercicio de la actividad económica (arts. 139.1 y 149.1.1), sin los cuales no es posible alcanzar en el mercado nacional el grado de integración que su carácter unitario impone».

La cita de esta sentencia hace innecesario insistir. Los espectáculos taurinos constituyen el último y más visible eslabón de una compleja cadena de actividades económicas muy variadas, que arranca de la cría del ganado bravo en el campo y que emplea a cerca de 180.000 personas, aportando en su conjunto al PIB nacional más de 2.500 millones de euros cada año.

Que un sector o subsector económico de este porte no puede ser mutilado por decisiones unilaterales adoptadas por las Comunidades Autónomas es algo que me parece indiscutible, a menos que se niegue cualquier significado a la regla 13 . $^{a}$ del art. 149.1 de la Constitución.

Dista mucho de estar claro que la competencia que el art. 116.1.d) del nuevo Estatuto de Cataluña atribuye a la Generalitat en materia de protección de los animales pueda amparar la prohibición de las corridas de toros decretada por la Ley 28/2010, porque, como antes dije, esa competencia, tal y como está formulada, es sólo una especificación de las que le corresponden en el ámbito de la agricultura, la ganadería y los aprovechamientos forestales con el que las corridas de toros no tiene, como es obvio, otro punto de conexión que el de la cría del ganado bravo y las condiciones sanitarias del mismo.

Sería necesaria, por tanto, una interpretación extremadamente laxa del citado precepto estatutario para poder entender incluida dentro de él la prohibición de los festejos taurinos, pero, incluso dejando esto a un lado y aceptando en términos puramente hipotéticos que pudiera serlo, dicha prohibición unilateral tropezaría, como ya he dicho, con el obstáculo insalvable que el propio precepto establece: el del respeto al orden económico general cuya determinación básica es competencia del Estado.

Nótese que Cataluña no es tierra de toros, excepción hecha de las tierras del Ebro en las que pasta el ganado que se utiliza en los corre-bous y sólo ellos. La prohibición de las corridas de toros no afecta a los ganaderos de Cataluña; afecta y de modo importante además en la medida en que la plaza de toros de Barcelona es una plaza de primera categoría de las principales de España a todos los ganaderos de bravo del resto del país. Y lo mismo puede decirse de los demás empresarios, lidiadores y profesionales de todo tipo vinculados de un modo u otro a la «industria del toro». En una u otra medida todos resultan afectados por la prohibición porque éste es un mercado único por sus propias características naturales, que exige inexcusablemente unas reglas también únicas.

A estas limitaciones intrínsecas, que resultan del propio precepto estatutario atributivo del título competencial invocado por la Ley 28/2010, todavía hay que añadir las que impone su confrontación con las normas materiales de la Constitución y, en concreto, con los derechos fundamentales que ésta reconoce a todos los ciudadanos.

El tema ha sido cuidadosamente analizado por G. DOMÉnECH PASCUAL (vid. «La prohibición de las corridas de toros desde una perspectiva constitucional», en El cro- 
nista del Estado social y democrático de Derecho, núm. 12, 2010, 16 y 17), a cuyo estudio me remito ahora.

Me limitaré a recordar simplemente que la prohibición de las corridas de toros entra en colisión con un buen número de derechos fundamentales y, muy especialmente, con el derecho a trabajar y elegir - y ejercer- libremente profesión u oficio, con la libertad de empresa, con la libertad de creación artística, con el derecho de acceso a la cultura en todas sus manifestaciones y con la libertad genérica de actuar que a todo ciudadano corresponde y de modo particular con el derecho de todos ellos a administrar su propio ocio, derechos que tienen un inequívoco reconocimiento en los arts. 1.1, 10, 16, 20, 35, 38 y 44 de la Constitución.

Aunque se acepte, como DomEnECH sostiene, que los derechos fundamentales pueden ser legítimamente restringidos en nombre de la protección de los animales, a pesar de que ésta no tenga el rango propio de un valor constitucional y sea simplemente un fin constitucionalmente lícito, es forzoso concluir que esa restricción tendría que ser proporcionada para poder ser constitucionalmente admitida.

Pudo considerarse así la medida inicialmente adoptada por la Ley de Protección de los Animales, de 4 de marzo de 1988, que limitó las corridas de toros a las plazas de toros permanentes ya existentes en ese momento en Cataluña y así lo entendió la Sentencia del Tribunal Supremo de 20 de octubre de 1998, pero difícilmente puede juzgarse del mismo modo la radical prohibición del espectáculo, que da preferencia absoluta a la protección de los animales, que, como ya se ha dicho, es sólo un fin constitucionalmente lícito y no un valor constitucional en sentido propio, sobre los derechos fundamentales de las personas que son «fundamento del orden político y de la paz social», según proclama el art. 10.1 de la Constitución.

Creo por todo ello que la Ley del Parlamento de Cataluña 28/2010, de 3 de agosto, no puede considerarse conforme a la Constitución, por lo que debe ser anulada en estimación del recurso de inconstitucionalidad interpuesto contra la misma el 27 de octubre último por setenta y dos Senadores del Grupo Parlamentario Popular del Senado. 